\title{
Long-term administration of desferrioxamine in thalassaemia major
}

\author{
R. SESHADRI, JOHN H. COLEBATCH, PATRICIA GORDON, and HENRY EKERT \\ From the Haematology Research Unit, Royal Children's Hospital Research Foundation, Melbourne, Australia
}

\begin{abstract}
Seshadri, R., Colebatch, J. H., Gordon, P., and Ekert, H. (1974). Archives of Disease in Childhood, 49, 621. Long-term administration of desferrioxamine in thalassaemia major. Studies of desferrioxamine (DFA) as a specific iron-chelating agent in the treatment of haemosiderosis have been reported in various conditions, but there has been only limited evaluation of its long-term use in thalassaemia major. In the present study $1 \mathrm{~g}$ DFA was given intramuscularly daily 6 days per week in 3 patients for 5 to 8 years, and in another 7 patients for 10 to 22 months. In addition, $500 \mathrm{mg}$ DFA was added to each unit of donor blood at the time of transfusions. Urinary iron excretion after DFA was estimated using atomic absorption spectrophotometry both before and periodically during DFA treatment. During follow-up, cardiac and liver functions were assessed by ECG, chest $x$-ray, and liver function tests.

The results show that DFA therapy increased urinary iron excretion, and that this was associated with a significant improvement in the clinical symptoms and signs of haemosiderosis and with return towards normal in the ECG and liver function tests.
\end{abstract}

The majority of children with thalassaemia major who do not succumb to the complications associated with severe anaemia nor to postsplenectomy infection usually die during the second or the third decade from intractable cardiac failure, liver cirrhosis, or diabetes mellitus. The pathogenesis of these complications is based on an excessive deposition of iron in vital organs which is associated with or followed by a steadily progressive fibrosis (Engle, Erlandson, and Smith, 1964; Fink, 1964; Ellis, Schulman, and Smith, 1954).

The iron-chelating agents desferrioxamine (DFA) and diethylenetriamine penta-acetic acid have been used for removing iron from patients with chronic iron overload. Of these two agents, DFA is easier to administer as it can be given intramuscularly and it is well tolerated. Most reports on the use of DFA in thalassaemia were confined to short-term trials (Smith, 1962; Hwang and Brown, 1964; McDonald, 1966; Diwany et al., 1968; Markum et al., 1969). Moreover, measurement of urinary iron excretion was the only criterion of response, and this does not provide evaluation of its clinical benefits. In a general review of the clinical usefulness of chelating agents published in 1969, Waxman and Brown concluded that, 'To date the long-term management

Received 21 January 1974. of iron overload in patients with thalassaemia has been disappointing and initial hopes have not been realized'.

This communication presents the results of a long-term trial of therapy with DFA administered by intramuscular injection daily to children suffering from thalassaemia major with haemosiderosis. The results suggest that DFA reduced the clinical effects of haemosiderosis including the abnormal liver and cardiac functions.

\section{Patients and methods}

Twelve patients with thalassaemia major, 7 of whom were Italian, 3 Greek, and 2 Turkish, were studied. 4 were boys and 8 were girls, their ages ranging from 6 to 14 years at the start of daily treatment with DFA. All had received transfusions at intervals of 1 to 4 months for periods ranging from 6 to 20 years. The pretransfusion haemoglobin level was usually 5.5 to $6.5 \mathrm{~g} / 100 \mathrm{ml}$. The total volume of blood received up to the time of analysis ranged from 80 to 250 units. Each patient had clinical signs suggesting iron overload, e.g. skin pigmentation, liver enlargement.

DFA was administered intramuscularly in doses of $1 \mathrm{~g}$ daily for 6 days a week. It was dissolved in 2 to $3 \mathrm{ml}$ water. Injections were usually given by a district nurse, but 2 girls, now 21 and 13 years of age, have been taught to give their own injections. The duration of treatment at the time of analysis was from 5 to 8 years in 3 patients, 
and from 10 to 22 months in 7 patients. From 1965 onwards, in addition, $500 \mathrm{mg}$ DFA were added to each $250 \mathrm{ml}$ packed red blood cells at the time of transfusion. In 2 children who were not under our care, DFA treatment was discontinued after 2 to 4 months because of emotional problems attributed to the injections; 1 of these has resumed daily injections since the results of this study were analysed.

24-hour urinary iron excretion after $1 \mathrm{~g} \mathrm{DFA}$ i.m. was determined before iron chelation treatment and periodically during treatment to assess the effect of DFA (Zettner and Mansbach, 1965). As the optimal dose of DFA is not known in children, the dose was arbitrarily chosen as $1 \mathrm{~g}$ irrespective of the age of the patient. This dose of DFA, when calculated in relation to the patient's body surface area, varied from $568 \mathrm{mg}$ to $1100 \mathrm{mg} / \mathrm{m}^{2}$ per day.

Cardiac and liver functions were assessed before and periodically during treatment by clinical examination, ECG, chest $x$-ray, and liver function tests (serum bilirubin, serum glutamic oxaloacetic transaminase (SGOT), and plasma protein electrophoresis). Immunoglobulin levels were estimated by radial immunodiffusion.

\section{Results}

In Table I are listed the clinical details relevant to the DFA-induced urinary iron excretion test and the results of this test when performed just before starting long-term daily DFA treatment and from 10 months to 8 years after. The basal 24-hour excretion ranged from 0.1 to $1.6 \mathrm{mg} / \mathrm{m}^{2}$ body surface area with a median of $0 \cdot 7$. The test dose of DFA ( $1 \mathrm{~g}$ ) increased the 24-hour urinary iron excretion to levels that ranged from $2 \cdot 4$ to $13 \cdot 8$ $\mathrm{mg} / \mathrm{m}^{2}$ with a median of $4 \cdot 2$. These levels were 3 to 100 times higher than the corresponding base- lines. After daily DFA treatment for various periods no consistent change occurred. The 4 patients (Cases 5, 7, 9, and 10) in whom a marked decrease in the amount of urinary iron was observed had undergone splenectomy 3 to 6 months before retesting. We have previously shown that DFAinduced urinary iron excretion decreases markedly after splenectomy (Seshadri, Colebatch, and Fisher, 1974).

Subjective assessment. 5 patients were able to appreciate subjective improvement in their health after starting DFA treatment. This included a lightening of skin pigmentation and an improved exercise tolerance. 2 of them, both 21 years of age, have been well enough to obtain employment and they attend hospital only for blood transfusion 4 to 6 times a year. The 3 other patients attend school regularly and are able to take part in normal school activities. The remaining 5 patients were probably too young to appreciate any changes.

\section{Objective assessment.}

Cardiac function (Table II). 5 patients (Cases 1, $2,3,6$, and 8 ) had had congestive cardiac failure and 2 of them pericarditis before DFA treatment began. The 2 patients with pericarditis had received digoxin daily for several months before DFA therapy. These 5 patients had moderate cardiomegaly as assessed by the cardiothoracic ratio which ranged from 0.54 to 0.6 . At the time of study after DFA treatment, all 5 were free from congestive cardiac failure as shown by the absence of oedema, improved exercise tolerance, and a decreased liver size.

TABLE I

Details of patients receiving long-term DFA treatment

\begin{tabular}{|c|c|c|c|c|c|c|c|}
\hline \multirow{3}{*}{ Case no. } & \multirow{3}{*}{$\begin{array}{l}\text { Age after DFA } \\
\text { treatment/sex }\end{array}$} & \multirow{3}{*}{$\begin{array}{l}\text { Duration of } \\
\text { treatment } \\
\text { (mth) }\end{array}$} & \multicolumn{2}{|c|}{$\begin{array}{l}\text { Total blood transfusion } \\
\text { (units) }\end{array}$} & \multicolumn{3}{|c|}{ Urinary iron excretion } \\
\hline & & & \multirow{2}{*}{$\begin{array}{l}\text { During } \\
\text { patient's life }\end{array}$} & \multirow{2}{*}{$\begin{array}{c}\text { During DFA } \\
\text { treatment }\end{array}$} & \multirow{2}{*}{$\begin{array}{c}\text { Basal } \\
\left(\mathrm{mg} / \mathrm{m}^{2} \text { in } 24 \mathrm{hr}\right)\end{array}$} & \multicolumn{2}{|c|}{$\begin{array}{l}\text { After } 1 \mathrm{~g} \text { DFA i.m. } \\
\left(\mathrm{mg} / \mathrm{m}^{2} \text { in } 24 \mathrm{hr}\right)\end{array}$} \\
\hline & & & & & & $\begin{array}{l}\text { Before long-term } \\
\text { DFA treatment }\end{array}$ & $\begin{array}{l}\text { After } 10 \text { mth- } 8 \\
\text { yr of treatment }\end{array}$ \\
\hline $\begin{array}{c}1+ \\
2 t \\
3 t \\
4 t \\
5 \\
6 t \\
7 \\
8 \\
9 \\
10\end{array}$ & $\begin{array}{c}21 / \mathrm{M} \\
21 / \mathrm{F} \\
15 / \mathrm{M} \\
12 / \mathrm{F} \\
13 / \mathrm{F} \\
13 / \mathrm{F} \\
10 / \mathrm{M} \\
9 / \mathrm{F} \\
7 / \mathrm{F} \\
10 / \mathrm{F}\end{array}$ & $\begin{array}{l}7 \frac{1}{2} \mathrm{yr} \\
8 \mathrm{yr} \\
5 \mathrm{yr} \\
22 \\
20 \\
12 \\
11 \\
12 \\
11 \\
10\end{array}$ & $\begin{array}{r}250 \\
240 \\
140 \\
80 \\
210 \\
165 \\
122 \\
136 \\
110 \\
119\end{array}$ & $\begin{array}{r}87 \\
106 \\
57 \\
23 \\
52 \\
21 \\
34 \\
24 \\
36 \\
27\end{array}$ & $\begin{array}{l}0 \cdot 7 \\
0.9 \\
0 \cdot 1 \\
0 \cdot 7 \\
0 \cdot 4 \\
1 \cdot 6 \\
0 \cdot 9 \\
0 \cdot 3 \\
0 \cdot 1 \\
1 \cdot 5\end{array}$ & $\begin{array}{r}2 \cdot 5 \\
3 \cdot 1 \\
6 \cdot 1 \\
4 \cdot 0 \\
4 \cdot 5 \\
8 \cdot 7 \\
13 \cdot 8 \\
2 \cdot 4 \\
10 \cdot 0 \\
13 \cdot 0\end{array}$ & $\begin{array}{l}6 \cdot 5 \\
4 \cdot 5 \\
4 \cdot 6 \\
7 \cdot 0 \\
2 \cdot 0 \ddagger \\
- \\
2 \cdot 0 \ddagger \\
2 \cdot 1 \\
1 \cdot 6 \ddagger \\
5 \cdot 4 \ddagger\end{array}$ \\
\hline
\end{tabular}

$\star 1$ unit of blood $=250 \mathrm{ml}$ packed red blood cells.

+Splenectomy before DFA treatment.

¥Splenectomy 3 to 6 months before post-treatment DFA urinary iron excretion text. 
TABLE II

Cardiac status before and after DFA treatment

\begin{tabular}{|c|c|c|c|c|c|c|c|}
\hline \multirow{2}{*}{ Case no. } & \multirow{2}{*}{ Age (yr) } & \multicolumn{2}{|c|}{ Cardiothoracic ratio } & \multicolumn{2}{|c|}{ ECG } & \multicolumn{2}{|c|}{ Complication } \\
\hline & & Before & After & Before & After & Before & After \\
\hline 1 & 21 & $\star$ Increased & 0.55 & Abnormal & $\mathbf{N}$ & $\begin{array}{l}\text { CCF-peri- } \\
\text { carditis }\end{array}$ & Nil \\
\hline 2 & 21 & $\star$ Increased & 0.52 & Abnormal & $\mathbf{N}$ & $\begin{array}{l}\text { CCF-peri- } \\
\text { carditis }\end{array}$ & $\mathrm{Nil}$ \\
\hline 3 & 15 & 0.60 & 0.52 & Abnormal & $\mathrm{N}$ & CCF & Nil \\
\hline 5 & 13 & 0.45 & 0.43 & $\mathrm{~N}$ & $N$ & $\mathrm{Nil}$ & $\mathrm{Nil}$ \\
\hline 6 & 13 & 0.54 & 0.52 & $\mathrm{~N}$ & $N$ & CCF & $\mathrm{Nil}$ \\
\hline 7 & 10 & 0.50 & 0.50 & $\mathbf{N}$ & $N$ & Nil & Nil \\
\hline 8 & 9 & 0.54 & 0.56 & Abnormal & $\mathbf{N}$ & CCF & Nil \\
\hline 9 & 7 & 0.51 & 0.50 & $\mathrm{~N}$ & $\mathrm{~N}$ & Nil & $\mathrm{Nil}$ \\
\hline 10 & 10 & 0.50 & 0.50 & $\mathrm{~N}$ & $\mathrm{~N}$ & Nil & Nil \\
\hline
\end{tabular}

CCF, congestive cardiac failure. $\mathrm{N}$, normal.

$\star X$-rays no longer available for measurement.

Cardiomegaly decreased in 4 patients (cardiothoracic ratio $0 \cdot 52-0 \cdot 55$ ).

ECG was abnormal before DFA treatment in 4 patients. Case 1 showed ST-segment depression and inverted T-wave in left chest leads when he had pericarditis and congestive cardiac failure. During treatment with DFA, signs of cardiac failure disappeared and ECG was normal at the time of the later reappraisal. Case 2 had flattened $\mathrm{T}$-wave only. Case 3 had left ventricular hypertrophy, inversion of T-wave, and ST-segment depression. Case 8 had left ventricular hypertrophy on voltage criteria. None had arrhythmia. In each of these patients ECG returned to normal after DFA treatment.

Before DFA treatment 5 patients, aged 7 to 13 years, had no abnormal cardiac function detectable clinically or on ECG and chest $x$-ray. They continue to have normal cardiac function with no episodes of pericarditis or of congestive cardiac failure. Up to the time of this analysis all of these patients had continued to receive their transfusions when the $\mathrm{Hb}$ level was $5 \cdot 5$ to $6 \cdot 5 \mathrm{~g} / 100 \mathrm{ml}$.

Liver function (Table III). All 10 patients had marked liver enlargment before DFA treatment, the liver edge being palpable 10 to $16 \mathrm{~cm}$ below the costal margin in 6 patients and at about $6 \mathrm{~cm}$ in the other 4. After DFA treatment, 4 patients had marked decrease in liver size, the edge receding by 4 to $14 \mathrm{~cm}$ (mean $10 \mathrm{~cm}$ ). Of the 6 other children, who had had treatment for only 10 to 22 months, 5 showed smaller decreases in liver size, and in 1 there was no change.

Abnormal liver function tests were present before DFA treatment in all patients except the youngest, aged 6 years. The abnormalities were raised levels of serum bilirubin ranging from 1 to $3 \mathrm{mg} / 100 \mathrm{ml}$, SGOT ranging from 40 to 148 (SF) units/1., and 4 patients had an abnormal plasma protein electrophoretic pattern with raised $\gamma$-globulin. Quantitative immunoglobulin estimations done in 6 patients showed normal results in 2 , conspicuously raised levels of both IgG and IgM in 1, and conspicuously raised levels of IgG, IgM, or IgA each in 1 of the other 3. In the 4 earliest patients, no pretreatment estimation was done, but semiquantitative estimations done in 1969 showed marked rise of all 3 classes of immunoglobulins.

After DFA treatment serum bilirubin levels did not change significantly (range $1 \cdot 1-2 \cdot 6 \mathrm{mg} / 100 \mathrm{ml}$ ). However, the mean SGOT level decreased from 102 units/l. (range 40-148) to 59 units/l. (range 15-120). In 6 patients this decrease was considerable, in 2 it was negligible, and in 2 others the level was slightly increased.

The plasma protein electrophoretic pattern returned to normal after DFA treatment in 3 of the 4 patients in whom it had been abnormal. No consistent change in the levels of IgG and IgM were noted, but in 4 patients IgA levels, which were raised before treatment, returned to normal.

Adverse side effects. The injection site became sore in 3 patients on 4 occasions, but the inflammation subsided within a week. None of the patients showed a hypersensitivity reaction to DFA. Slit lamp examination was done in each patient; none had cataracts.

\section{Discussion}

The evaluation of long-term iron chelation therapy is difficult in patients with thalassaemia major who continue to receive blood transfusions. 
Liver function tests before

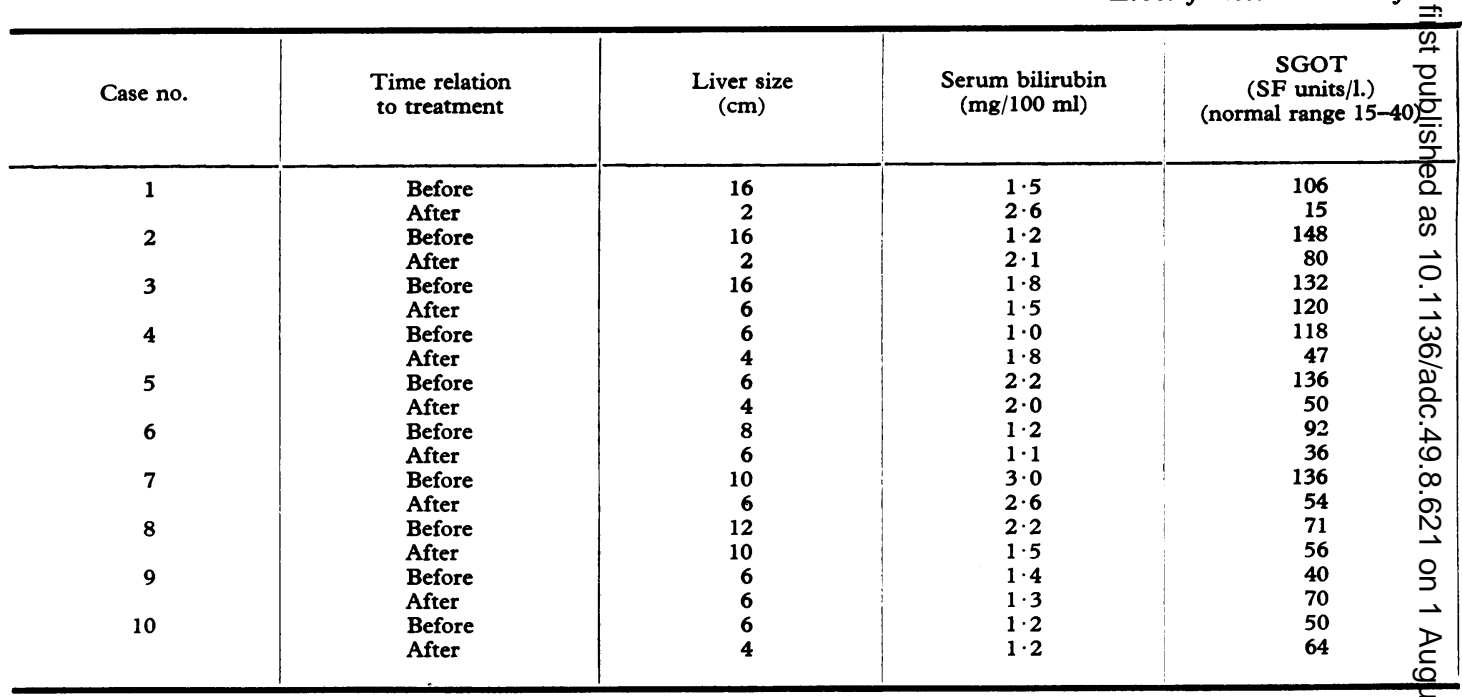

$\mathrm{N}$, normal range. $\uparrow$, Raised levels (semiquantitative).

In such cases assessment of the efficacy of DFA can be approached in the following ways. (1) By iron balance studies to estimate the amount of iron lost for comparison with the increased iron load obtained from transfusions and excessive absorption; (2) by serial estimation of parenchymal cell iron by histochemical or biochemical methods; and (3) by observing improvement in the clinical manifestations of haemosiderosis. The third method was the major one used in this study and the results suggest that DFA given daily in thalassaemia major is an effective agent for preventing the fatal consequences of severe haemosiderosis, if it is started at an early enough age, and that it possibly reverses existing pathology caused by haemosiderosis.

The regimen of chelation therapy outlined in this study has been more intensive and it has extended over a longer period than in most other studies. Factors that made it possible to continue this intensive regimen were (1) ready availability of DFA in Australia, (2) the singular absence of untoward side effects, and (3) arrangements for the injections to be given at the patient's home, which does not interfere unduly with the child's daily life.

Treatment with DFA was started in children usually above the age of 8 years and/or in children who had received more than 100 units of blood. One exception was an Italian girl (Case 9) who was only 6 years old when daily DFA treatment began. The dose of DFA chosen was $1 \mathrm{~g}$ daily irrespective of age and size of the patient as this dose was a convenient one for outpatient use. 6 children had undergone splenectomy before starting DFA therapy and 4 were splenectomized during this treatment.

It has been shown that calculations of DFAinduced iron loss based on urinary excretion figures underestimate the total chelating effect of DFA, as faecal iron excretion may amount to as much as 37 to $100 \%$ of the urinary loss (Lukens and Neuman, 1971). Moreover, when assessing the effectiveness of DFA, allowance has to be made for factors such as age, degree of anaemia (Fielding, 1970), and splenectomy (Seshadri et al., 1974) which influence the amount of iron excretion. Our earlier observations on DFA-induced urinary iron excretion suggested that DFA may not be effective in removing the excess iron from the myocardium and liver in the presence of a large spleen (Seshadri et al., 1974).

In this study, probably because of the factors mentioned above, the amount of iron excreted varied among patients and at different periods in the same patient. Due to similar reasons a close correlation between body iron burden (expressed as units of blood received) and DFA-induced iron excretion was not observed even though DFA increased the urinary iron excretion 3 to 100 times above the basal level.

An early sign of clinical improvement after DFA treatment was decrease in skin pigmentation, usually seen within 2 to 6 months of therapy. Though the 
III

and after DFA treatment

\begin{tabular}{|c|c|c|c|c|}
\hline \multirow{2}{*}{$\begin{array}{l}\text { Albumin } \\
(\mathrm{g} / 100 \mathrm{ml})\end{array}$} & \multirow{2}{*}{$\begin{array}{l}\text { Globulin } \\
(\mathrm{g} / 100 \mathrm{ml})\end{array}$} & \multicolumn{3}{|c|}{ Immunoglobulin $(\mathrm{mg} / 100 \mathrm{ml})$} \\
\hline & & $\begin{array}{c}\text { IgG } \\
\text { (normal range 580-2000) }\end{array}$ & $\begin{array}{c}\text { IgM } \\
\text { (normal range 35-145) }\end{array}$ & $\begin{array}{c}\text { IgA } \\
\text { (normal range } 38-320)\end{array}$ \\
\hline $\begin{array}{l}- \\
4 \cdot 2 \\
4 \cdot 4 \\
4 \cdot 2 \\
2 \cdot 9 \\
3 \cdot 9 \\
3 \cdot 2 \\
4 \cdot 8 \\
4 \cdot 1 \\
3 \cdot 7 \\
3 \cdot 4 \\
3 \cdot 6 \\
3 \cdot 8 \\
4 \cdot 1 \\
3 \cdot 6 \\
3 \cdot 3 \\
3 \cdot 6 \\
4 \cdot 0 \\
3 \cdot 1 \\
4 \cdot 0\end{array}$ & $\begin{array}{l}-1 \\
3 \cdot 9 \\
4 \cdot 1 \\
2 \cdot 9 \\
4 \cdot 6 \\
4 \cdot 4 \\
4 \cdot 7 \\
2 \cdot 7 \\
3 \cdot 7 \\
3 \cdot 0 \\
4 \cdot 4 \\
4 \cdot 2 \\
2 \cdot 9 \\
2 \cdot 4 \\
3 \cdot 5 \\
3 \cdot 3 \\
2 \cdot 8 \\
3 \cdot 7 \\
2 \cdot 7 \\
2 \cdot 7\end{array}$ & $\begin{array}{c}\uparrow \\
1600 \\
\uparrow \\
1800 \\
\uparrow \\
3700 \\
\uparrow \\
2180 \\
3700 \\
2850 \\
1800 \\
2650 \\
1390 \\
2000 \\
1950 \\
- \\
1450 \\
1674 \\
2200 \\
1300\end{array}$ & $\begin{array}{c}\uparrow \\
180 \\
\uparrow \\
190 \\
\uparrow \\
265 \\
\uparrow \\
116 \\
140 \\
135 \\
92 \\
153 \\
188 \\
260 \\
106 \\
108 \\
119 \\
350 \\
115\end{array}$ & $\begin{array}{c}\uparrow \\
300 \\
\uparrow \\
260 \\
\uparrow \\
245 \\
\uparrow \\
290 \\
120 \\
104 \\
460 \\
306 \\
275 \\
230 \\
270 \\
\overrightarrow{98} \\
92 \\
143 \\
110\end{array}$ \\
\hline
\end{tabular}

exact mechanism of action of DFA in producing this effect is unknown, it has been suggested that DFA inhibits the oxidation of adrenalin to melanin via adrenochrome by reducing the concentration of $\mathrm{Fe}^{+++}$ions which act as catalysers (Wöhler, 1964). Though the decrease in skin pigmentation may appear only a trivial benefit, it has encouraged 3 girls in this study to continue the daily treatment for cosmetic reasons alone.

In thalassaemia major symptoms of heart failure attributable to cardiomyopathy have usually become chronic by the age of 15 years. Though a high transfusion regimen decreased the cardiothoracic ratio of patients with thalassaemia major (Beard, Necheles, and Allen, 1969), it has not reduced the mortality rate (Wolman and Ortolani, 1969). In the present study the changes in cardiothoracic ratio in Table II were probably the result of longterm treatment with DFA. They were not due to changes in the degree of anaemia as $\mathrm{Hb}$ levels at which transfusions were given before and during chelation therapy were comparable. Until 1 month ago there were 7 patients aged 16 to 19 years with thalassaemia major attending this hospital. In 4 of these 7 patients, who had not received daily DFA treatment (they were not under our care), severe cardiomyopathy developed. 2 of these died recently, 1 with diabetes mellitus and hypoparathyroidism secondary to haemosiderosis; the other 2 have impaired cardiac function. The remaining 3 patients, who received daily DFA treatment, are Cases 1,2, and 3 in the present study. In these 3 the improvement observed in cardiac status, e.g. absence of congestive cardiac failure and return of an abnormal ECG to normal, suggests that intensive long-term DFA treatment prevented the myocardial damage that follows iron deposition.

A significant decrease in liver size occurred in patients who had received DFA treatment for a long time. This was preceded by an improvement in liver function tests, especially SGOT levels. Though raised SGOT levels in frequently transfused thalassaemic children have been associated with viral hepatitis in other reports, in this study repeated tests to detect hepatitis-associated antigen and antibody were negative in every case. This is probably due to the low incidence of carriers with hepatitis-associated antigen among blood donors in Melbourne. Repeated viral studies were also performed to detect transfusion-transmitted cytomegalovirus infection. Though all the patients had antibodies to cytomegalovirus in their serum, none had evidence of recent infection.

Abnormalities of the plasma protein pattern are often noticed in thalassaemia. The most common of these is a raised level of $\gamma$-globulin. The cause of this is not definitely known, but it is probably due to an increased reticuloendothelial activity in response 
to repeated infections. Wasi, Wasi, and Thongcharoen (1971) in Thailand noted an increase in IgA and a decrease in IgM level after splenectomy and suggested that the increase in IgA level was due to liver damage secondary to iron deposition. In our study, all except 1 patient had normal plasma protein levels after DFA treatment. IgA levels were raised before DFA treatment in 4 patients, but during treatment they returned to normal levels and remained normal.

In this study, the assessment of long-term DFA therapy by daily injections has been based on serial measurements-clinical, radiological, electrocardiographic, and biochemical - with special regard to the heart and liver. This was not a controlled trial, but its findings provided strong circumstantial evidence that this form of chelation therapy has benefits that are clinically significant. It is logical to presume that the decreased size and improved function of the heart and liver resulted from removal of excess iron from these organs. The marked increase in urinary iron excretion after a test dose of DFA is in keeping with this explanation, but its proof requires the demonstration of reduced parenchymal iron in these organs. Most of our patients have migrated to Australia so recently that cultural and language difficulties have made it impracticable as yet to do paired liver biopsies, except in 1 patient in whom no convincing change was shown by histochemical technique. Biochemical estimation may be more satisfactory, as Flynn (1973) has recently reported a highly significant difference in the mean liver iron concentration between patients treated with DFA and controls, even though these patients received only half as much DFA daily as did those in the present study.

We thank Dr. A. W. Venables, Director of the Cardiology Unit, for expert advice in cardiological assessment and management ; the staff of the Department of Pathology for investigations; the Departments of Ophthalmology and Radiology for assessments; and Physicians of the Senior Medical Staff for referral of 4 of the patients.
REFERENCES

Beard, M. E., Necheles, T. F., and Allen, D. M. (1969). Clinical experience with intensive transfusion therapy in Cooley's anemia. Annals of the New York Academy of Sciences, 165, 415.

Diwany, M., Gabr, M., El Hefni, A., and Mokhtar, N. (1968). Desferrioxamine in thalassaemia. Archives of Disease in Childhood, 43, 340.

Ellis, J. T., Schulman, I., and Smith, C. H. (1954). Generalized siderosis with fibrosis of liver and pancreas in Cooley's (Mediterranean) anemia: with observations on the pathogenesis of the siderosis and fibrosis. American fournal of Pathology, 30, 287.

Engle, M. A., Erlandson, M., and Smith, C. H. (1964). Late cardiac complications of chronic, severe, refractory anemia with hemochromatosis. Circulation, 30, 698.

Fielding, J. (1970). Storage iron and desferrioxamine. Proceedings of the Royal Society of Medicine, 63, 1218.

Fink, H. (1964). Transfusion hemochromatosis in Cooley's anemia. Annals of the New York Academy of Sciences, 119, 680.

Flynn, D. M. (1973). Five-year controlled trial of chelating agents in treatment of thalassaemia major. (Read at the Annual Meeting of the British Paediatric Association, 3-7 April 1973.) Archives of Disease in Childhood, 48, 829.

Hwang, Y. F., and Brown, E. B. (1964). Evaluation of desferrioxamine in iron overload. Archives of Internal Medicine, 114, 741 .

Lukens, J. N., and Neuman, L. A. (1971). Excretion and distribution of iron during chronic deferoxamine therapy. Blood, 38, 614.

McDonald, R. (1966). Deferoxamine and diethylenetriaminepentaacetic acid (DTPA) in thalassemia. Fournal of Pediatrics, $69,563$.

Markum, A. H., Iskandar, W., Kho, L. K., and Odang, O. (1969). Iron excretion in thalassaemia after the administration of chelating agents. Paediatrica Indonesiana, 9, 89.

Seshadri, R., Colebatch, J. H., and Fisher, R. (1974). Urinary iron excretion in thalassaemia after desferrioxamine administration. Archives of Disease in Childhood, 49, 195.

Smith, R. S. (1962). Iron excretion in thalassaemia major after administration of chelating agents. British Medical fournal, 11, 1577.

Wasi, C., Wasi, P., and Thongcharoen, P. (1971). Serm-immunoglobulin levels in thalassaemia and the effects of splenectomy. Lancet, 2, 237.

Waxman, H. S., and Brown, E. B. (1969). Clinical usefulness of iron chelating agents. In Progress in Hematology, Vol. 6, p. 338. Ed. by E. B. Brown and C. V. Moore. Grune and Stratton, New York and London.

Wöhler, F. (1964). Diagnosis of iron storage diseases with desferrioxamine. Acta Haematologica, 32, 321.

Wolman, I. J., and Ortolani, M. (1969). Some clinical features of Cooley's anemia patients as related to transfusion schedules. Annals of the New York Academy of Sciences, 165, 407.

Zettner, A., and Mansbach, L. (1965). Application of atomic absorption spectrophotometry in the determination of iron in urine. American fournal of Clinical Pathology, 44, 517.

Correspondence to Dr. J. H. Colebatch, c/o Royal Children's Hospital Research Foundation, Parkville, Victoria 3052, Australia. 